\title{
Fazendo a Base virar realidade: \\ competências e o germe da comparação ${ }^{1}$
}

\section{Making the Core come true:}

skills and the germ of comparison

\section{Transformando la Base en realidad:}

competencias y el germen de la comparación

\section{ELIZABETH FERNANDES DE MACEDO*}

Universidade do Estado do Rio de Janeiro, Rio de Janeiro- RJ. Brasil.

\begin{abstract}
RESUMO: Neste texto, foco, especificamente, em um conjunto de materiais que se dedica a "fazer a Base virar realidade nas salas de aula", produzido por uma articulação entre o MEC, as secretarias de educação e entidades do terceiro setor. Parto de uma noção pós-fundacional de política, segundo a qual toda hegemonia é marcada, desde o seu interior, por uma fratura e precisa, portanto, seguir sendo reinstituída. Dedico-me a entender como a noção de competência geral, que passou a estruturar a Base pós-impeachment, vem sendo significada no momento atual. Argumento que há um alinhamento da política educacional do País à governança da OCDE baseada na comparabilidade que, defendo, inviabiliza a educação como empreitada intersubjetiva. Por fim, sugiro o uso de outras referências para a construção de uma base de valorização profissional e condições de infraestrutura para uma educação de qualidade.
\end{abstract}

Palavras-chave: Políticas de currículo. BNCC. Competências. OCDE.

ABSTRACT: In this text, I focus, specifically, on a set of materials that is dedicated to "making the Core become reality in classrooms", produced by an articulation between the Ministry of Education (MEC), the departments of education and entities of the third sector. I begin

* É Doutora em Educação pela Universidade Estadual de Campinas. Atualmente é professora Titular da Universidade do Estado do Rio de Janeiro. É Cientista do Nosso Estado da FAPERJ, bolsista 1A do CNPq e procientista da FAPERJ/UERJ. E-mail: <elizabethmacedo@gmail.com>. 
with a post-foundational notion of politics, according to which all hegemony is marked from within, by a fracture and must therefore be re-stablished. I devote myself to understanding how the notion of general competence, which began to structure the post-impeachment core, is being signified at the moment. I argue that there is an alignment of the country's educational policy to OECD-based (Organisation for Economic Co-operation and Development) comparability, which, I argue, makes education as an intersubjective endeavor unfeasible. Finally, I suggest the use of other references to build a professional appreciation core and infrastructure conditions for quality education. Keywords: Curriculum policies. BNCC. Skills. OECD.

RESUMEN: En este texto, enfoco específicamente un conjunto de materiales dedicados a "transformar la Base en realidad en la clase", producida por una articulación entre el MEC, las secretarías de educación y las entidades del tercer sector. Empiezo desde una noción post-fundacional de política, según la cual toda hegemonía está marcada desde su interior por una fractura y necesita, por lo tanto, seguir siendo reinstituida. Me dedico a entender cómo la noción de competencia general que pasó a estructurar la Base post-impeachment ha sido significada en el momento actual. Argumento que hay una alineación de la política educativa del país con la gobernanza de la OCDE basada en la comparabilidad que, sostengo, hace que la educación sea inviable como un esfuerzo intersubjetivo. Finalmente, sugiero el uso de otras referencias para la construcción de una base de valoración profesional y condiciones de infraestructura para una educación de calidad.

Palabras clave: Políticas de currículo. BNCC. Competencias. OCDE.

\section{A Base não é currículo}

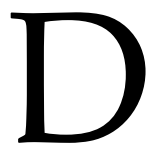

urante o longo processo que culminou com a aprovação da base nacional curricular comum para o ensino fundamental (BNCC) muitas foram as articulações políticas que buscaram hegemonizar sentidos para qualidade da educação. Burocracias de estado - MEC, secretarias de educação municipais e estaduais, Consed, Undime; professores e escolas mobilizados pelas consultas on-line levadas à cabo pelo MEC; movimentos sociais; associações de classe e de pesquisa; fundações ligadas a conglomerados privados; think tanks; redes como o Todos pela Educação e o Movimento pela 
Base; e universidades são alguns dos muitos sujeitos envolvidos no debate. Não apenas qualidade, mas justiça social e equidade, se tornaram termos disputados por perspectivas críticas, plurais e distintas, e por discursos neoliberais de perfil técnico, também eles heterogêneos. Por mais desigual que a luta por significação tenha sido (e sempre o seja), em função do elevado volume de recursos - públicos, em sua maioria, porque oriundos de renúncia fiscal - mobilizado por fundações e think tanks, antagonismos incrementaram as possibilidades de significação.

Parto do princípio, aqui como em minha trajetória de pesquisadora, de que ampliar a visibilidade dos antagonismos e complicar as hegemonias é sempre um bom caminho. Tentar encerrar a luta política - negando o antagonismo social -, mesmo que nunca se configure como uma alternativa possível ou viável, traz o gérmen do fascismo com suas certezas (Mouffe, 2017). Se é verdade que as certezas podem se agigantar com justificativas técnicas - assessoradas pelo dinheiro -, não foram menos numerosos, historicamente, momentos em que se impuseram pela coerção. E esse é, talvez, o perigo que vivemos atualmente e que já se insinuava quando da aprovação da Base. A guinada conservadora que culminou com o impeachment da presidenta Dilma Rousseff e a posterior eleição de Jair Bolsonaro produz um novo contexto, distinto daquele em que todo o debate da BNCC vinha sendo travado desde a promulgação da LDB, em 1996. Mesmo que eu não vá abordar tal guinada aqui, ela é parte importante do momento em que está se dando a implementação da Base, meu foco neste texto.

A aprovação da BNCC, em 2017, constitui um momento de inflexão da política pública em currículo no País. Ainda que tenha sempre havido algum nível de centralização curricular no Brasil, ela nunca chegou à definição do que deve ser ensinado em cada disciplina ao longo dos diferentes anos de escolarização em todo o território nacional. A BNCC representa, portanto, a hegemonia de certa concepção de educação e de escolarização. Na perspectiva pós-fundacional com a qual venho lendo as políticas, hegemonizar significa universalizar uma concepção particular, o que, no entanto, não é capaz de apagar o antagonismo que é constitutivo do social. Toda hegemonia é marcada, desde o seu interior, por uma fratura - o exterior constitutivo - e precisa seguir lutando para suturá-la, sem sucesso (LACLAU, 2011). Ou seja, a BNCC aí está - e isso importa porque ela desloca o poder, o que tem efeitos -, mas, para se manter efetiva na significação da educação e da escolarização, ela tem que seguir reiterando os sentidos que instaura. E esse processo, que vivemos hoje, é tão político e disputado quanto aquele que a instituiu.

Da compreensão pós-fundacional da política, trago a certeza de que não há a perder na política e ela é o motor deste texto. Infelizmente, também não há a ganhar, estamos enredados no que Lopes (2015) vai denominar de hiperpolitização. Será sempre necessário seguir deslocando aquilo que se apresenta como vitória e continuar expondo as fraturas que constituem os universais. Meu foco aqui será o momento atual, que, não por acaso, vem sendo chamado pelas políticas públicas de “implementação da Base nas 
redes de ensino de todo o País" ou de "(re) elaboração do currículo do seu Estado"2. De minha crença na hiperpolitização, fica claro que tomo todo e qualquer momento como instituinte do currículo [e de qualquer prática significante], independente de as forças envolvidas na formulação da BNCC assim o nominarem. Não deixa, no entanto, de ser animador ver o limite da norma curricular aceito por aqueles que a impõem.

O reconhecimento desse limite é umas das pequenas, mas importantes, vitórias da mobilização contra a BNCC. Arrisco generalizar que toda tradição curricular se dá conta de que o currículo - para ser currículo - precisa acontecer nas escolas (ou nos lugares e tempos em que acontecem). Em muitas dessas tradições, no entanto, a produção e a implementação curricular são tomados como momentos distintos, sendo este apenas a aplicação - ou a transposição - do que aquele instituiu. Esse é, sem dúvida, o modelo subjacente à proposta mesma da BNCC, modelo este tensionado durante o processo. $\mathrm{Na}$ primeira versão do documento, a participação da escola e mesmo dos sistemas locais de ensino era restrita à parte diversificada da Base:

Esses conhecimentos devem constituir a base comum do currículo de todas as escolas brasileiras embora não sejam, eles próprios, a totalidade do currículo, mas parte dele. Deve-se acrescer à parte comum, a diversificada, a ser construída em diálogo com a primeira e com a realidade de cada escola, em atenção não apenas à cultura local, mas às escolhas de cada sistema educacional sobre as experiências e conhecimentos que devem ser oferecidos aos estudantes e às estudantes ao longo de seu processo de escolarização (MEC, 2015: 15).

Nesta primeira formulação, até a definição de um projeto pedagógico - “arranjos na distribuição a cada ano" - era justificada apenas pela necessidade de considerar "especificidades locais e a articulação entre a parte comum e a diversificada" (p.16). Somente depois de muita luta política, o MEC assumiu, em seus documentos, que a Base não é currículo e que as redes locais e as escolas são as responsáveis pela elaboração dos currículos.

BNCC e currículos têm papéis complementares para assegurar as aprendizagens essenciais definidas para cada etapa da Educação Básica (BRASIL, 2017: 16).

Com a homologação da BNCC, as redes de ensino e escolas particulares terão diante de si a tarefa de construir currículos, com base nas aprendizagens essenciais estabelecidas na BNCC, passando, assim, do plano normativo propositivo para o plano da ação e da gestão curricular que envolve todo o conjunto de decisões e ações definidoras do currículo e de sua dinâmica (BRASIL, 2017: 20)

Ainda é visível, nesses dois estratos, uma formulação em que a experiência curricular nas escolas é nominada como currículo em ação - que demanda o seu par, o currículo formal $^{3}$. Mas há neles também o reconhecimento - uma exigência da negociação política -, de que a escola é um espaço em que o currículo é instituído e isso permite que a etapa atualmente em curso seja vivida de forma menos linear. De alguma forma, uma teorização que há 50 anos vem denunciando o caráter impositivo e desmobilizador de políticas 
que apostam na distinção entre produção e implementação curricular está lá na BNCC. Pode não ser muito - porque há intensa luta pela frente -, mas é a expressão de que é sempre possível perturbar os consensos políticos.

Neste texto, olho para os "guias" de implementação, propostos pela Undime e Consed com apoio de "entidades do terceiro setor", como um dos espaços em que se luta, hoje, por significar a Base. Tais documentos circulam pelas escolas em um momento em que muitos professores se sentem sobrecarregados tanto pelas transformações que a BNCC promete quanto pelos ataques constantes aos profissionais amplificados pelo apoio, entre outros, do próprio presidente da República. Têm, portanto, imagino, seu impacto ampliado junto aos docentes. Ao mesmo tempo, nos trabalhos que vimos desenvolvendo junto a vários municípios, temos percebido que há apego por aquilo que vinha sendo produzido nas escolas e muita resistência aos "guias" e às "agendas" elaborados centralmente. Se eles não são os únicos discursos em circulação, são parte da luta por significar educação e escola neste momento em que a Base é implementada.

Meu foco mais específico será um conjunto de materiais que se dedicam a "explicar" as competências gerais, estruturante da BNCC. Tal opção tem a ver com a relevância que a sua significação tem assumido nesta etapa, mobilizando os principais agentes privados. Ela se justifica, também, pelo fato de a inserção do conceito no documento encaminhado ao $\mathrm{CNE}$, e por ele aprovado, ter sido a principal mudança em relação às versões pré-impeachment.

\section{Um breve mapa das forças políticas}

Com a Base do Ensino Fundamental oficialmente aprovada pelo CNE em dezembro de 2017, iniciou-se o que o MEC e as secretarias de educação têm denominado de implementação. Como ocorreu durante a redação da Base, o processo tem sido conduzido pelos gestores públicos, com forte participação de fundações, think tanks e grupos educacionais ligados ao setor privado, assim como de movimentos sociais organizados por tais atores. Tendo em vista a nova configuração política do País, no entanto, as demandas críticas ou por justiça social têm tido menos representatividade nesta fase do que tiveram no início da elaboração do documento, conduzido pelas gestões do Partido dos Trabalhadores. A implementação parece, portanto, dominada pelas demandas por accountability, ainda que não se possa deixar de destacar o crescimento de demandas conservadoras ${ }^{4}$.

Talvez seja, ainda, cedo para avaliar o impacto dos discursos conservadores - prevalentes no MEC - no futuro da BNCC. A briga atual dos conservadores tem sido pela deslegitimação da escola como espaço público de formação e socialização. Se o ensino domiciliar foi a primeira bandeira, é importante lembrar que as bancadas pentecostais no Congresso Nacional, assim como o Movimento Escola sem Partido, foram importantes 
vozes contra a elaboração de uma Base. O argumento, à época, era de que ela consolidaria a intervenção do Estado na formação, negando à família o direito de educar suas crianças e seus adolescentes. Desde o início do Governo Bolsonaro, coincidência ou não, a implementação da Base não tem tido destaque no MEC. Nas 35 prioridades para os 100 primeiros dias de governo, apenas a criação de um programa de alfabetização foi apresentada pelo $\mathrm{MEC}$, sem menção à BNCC em si ou em sua relação com o referido programa. A fala do novo ministro na Câmara Federal, em maio de 2019, também não deu qualquer destaque à implementação da BNCC. O ProBNCC, criado em 2018 para apoiar a implementação da Base, somente foi retomado em início de abril, após pressão das secretarias e conselhos de educação $0^{5}$ por sua continuidade. No portal do MEC, não há praticamente nenhuma informação sobre a BNCC do Ensino Fundamental, sendo que as poucas notícias acessíveis datam de 2018. A página da Secretaria de Educação Básica não faz alusão à Base no conjunto de "documentos que norteiam a educação básica" nem no que classifica como "outros documentos fundamentais". Ademais, não há nenhuma alusão ao documento da BNCC nas publicações listadas no portal e nenhum link para a página da BNCC é visível no portal.

Trago essas ausências como possíveis evidências - e assumo que estou dando um chute no escuro - de que, em termos do Governo Federal, a implementação da Base não se configura como prioridade. Claro que se poderia argumentar que as políticas do MEC, e do próprio governo, têm sido erráticas e que tais ausências pouco significam. Ainda que reconhecendo uma certa desorganização por desconhecimento e desestruturação da máquina administrativa, entendo que há um projeto político claro sendo posto em ação pela hegemonia conservadora. Como ocorre em contextos políticos externos que têm servido de "modelo" para as forças conservadoras no Brasil, não há espaço, neste projeto, para currículos nacionais. Por mais que me posicione - como o faço - contrariamente à centralização curricular, os currículos nacionais produzidos sob a hegemonia do discurso neoliberal têm se pautado pela linguagem do republicanismo, da inclusão e do reconhecimento da diferença. Com isso não quero negar a oligarquização que tais políticas produziram nem o fato de terem buscado espraiar um pensamento único, razões que, para Mouffe (2018), levaram a uma crise de representação que culminou com o surgimento de populismos de direita. Quero apenas sugerir - e ficará apenas a sugestão, visto que este não é meu foco aqui - que não há espaço, no populismo de Bolsonaro, para tal linguagem. Talvez seja ainda muito cedo para apostar em como as articulações entre a clássica racionalidade neoliberal $^{6}$ e os populismos de direita vão ser produzidas ao longo do tempo.

Após este parênteses um tanto longo, quero voltar ao que há de concreto na implementação da Base. Atualmente, o movimento tem sido puxado pelos atores mais atuantes durante a fase de elaboração. Do ponto de vista do poder público e das burocracias de estado, o protagonismo tem sido das secretarias de educação e de seus coletivos - Consed e Undime. Como ocorreu ao longo de todo o processo, a articulação preferencial desses sujeitos segue sendo com as fundações e think tanks ligados à iniciativa privada, 
ou o que chamam de "terceiro setor" ${ }^{\prime 7}$. Em outros textos, analisei tais articulações tendo por inspiração o mapeamento das redes de política que Ball (2012) vem produzindo há uma década. Em estudos sobre as redes globais, referência para muitas pesquisas sobre as recentes políticas educacionais no Brasil (AVELLAR e BALL, 2019; HYPOLITO, 2015; MACEDO, 2014; SHIROMA, 2013), o autor (2012) define redes como "comunidades políticas descentradas, articuladas em torno de problemas sociais comuns, tendo em vista suas soluções" (p.5). Utilizando a metodologia de etnografia da rede, em co-autoria com Junemann, os autores mapeiam as articulações entre "capital financeiro filantrópico, think-tanks, partes dos governos e diversos políticos e atores políticos, ao longo dos partidos, nacionais e internacionais" (BALL e JUNEMANN, 2012: 85). Tal metodologia tem permitido perceber novas topologias políticas com as quais ainda não estamos acostumados nas análises políticas. Dicotomias clássica como público e privado, direita e esquerda tendem a colapsar em novas formas de sociabilidade.

Na agenda conjunta produzida por Consed e Undime, em março de 20198, a continuidade da implementação da BNCC surgiu como uma das demandas de secretários de educação ao MEC. O inegável compromisso dessas entidades com a implementação da base se materializa neste documento, no qual foi explicitada, ainda, a preocupação com as relações entre a Base, as avaliações de larga escala e a formação de professores. Como o documento é ainda muito inicial - e tópico -, mais do que analisá-lo, quero aqui destacar a participação de fundações privadas nesta etapa do processo. Em fins de abril, uma reunião de secretários estaduais e municipais de Educação com o MEC para discussão "de um plano de ação conjunto (...), uma agenda integrada" ${ }^{\prime}$, contou com "entidades do terceiro setor", nomeadamente, Instituto Natura, Ayrton Senna, Unibanco, Fundação Lemann e o Movimento Todos pela Educação. Parcerias como estas seguem sendo constantes durante a fase de implementação da Base, com a presença de tais entidades nos planejamentos municipais e estaduais ${ }^{10}$, assim como nas escolas. O link Base Nacional Comum na página da Undime leva direto ao Movimento pela Base Nacional Comum, este definido como "um grupo não governamental de profissionais da educação que desde 2013 atua para facilitar a construção de uma Base de qualidade"11. Em sua composição, o grupo conta com "pessoas e instituições que atuam na área de educação". No elenco de "pessoas", destacam-se gestores públicos e líderes de "entidades do terceiro setor" e, na lista de apoios institucionais, tais entidades dividem espaço com a Undime e o Consed.

Não trago esses vínculos para desqualificar [ou qualificar] as diferentes e diversas ações que vêm sendo levadas a cabo na fase de implementação da Base. Isso não quer dizer que não veja com preocupação as novas formas de sociabilidade que eles vão criando em áreas como a Educação. Diz apenas que, neste texto, tais vínculos são visibilizados para justificar a importância de analisar os materiais produzidos pelos parceiros "do terceiro setor". Afinal, eles são feitos parte da política curricular implementada pelos entes responsáveis pela gestão da educação pública. 


\section{BNCC como política global}

Nesta seção, proponho voltar a atenção para os materiais produzidos para "fazer a Base virar realidade nas salas de aula ${ }^{12 \prime}$. Parto da página do Movimento pela Base Nacional Comum e tenho por foco as 10 competências gerais, tema que ganha relevância no contexto da implementação.

Os dois principais links da página do Movimento pela Base referem-se à construção do documento e à sua implementação ${ }^{13}$, uma expressão de que se trata de processos relacionados, mas distintos. A implementação - que nos interessa neste texto - encontra-se subdividida em quatro entradas: guia redes, BNCC em profundidade, competências gerais e benchmarks internacionais. Na primeira, tem-se acesso a um guia de implementação "feito por gestores para gestores ${ }^{14 "}$, apresentando as "sete dimensões para orientar o processo de implementação da BNCC". A segunda, após pequenos vídeos sobre as competências gerais, realça as áreas de conhecimento e as disciplinas que as compõem. $\mathrm{Na}$ terceira, as competências gerais retornam e são exploradas em mais detalhes. Por fim, um link para referências internacionais é apresentado sob o título de benchmarks.

No que tange às competências gerais, o Movimento disponibiliza, entre outros, o 'Guia da Base dedicado às Competências Gerais ${ }^{15}$ ', de autoria da Nova Escola; um "curso on-line, gratuito e com certificação sobre as competências gerais, (...) elaborado [também] pela Nova Escola, em parceria com a Fundação Lemann e o Instituto Inspirare ${ }^{16^{\prime \prime}}$; a publicação 'Dimensões e Desenvolvimento das Competências Gerais na BNCC ${ }^{17 ’}$, parceria do Movimento com o Center for Curriculum Redesign; e uma plataforma 'Competências na $\mathrm{BNCC}^{18}$ ', de responsabilidade do Porvir, iniciativa do Instituto Inspirare. A autoria desses documentos mobiliza, além da Fundação Lemann - cujo protagonismo ao longo do processo de elaboração da BNCC é notório (Macedo, 2014) -, o Instituto Inspirare. Como a Lemann, tal Instituto se define como instituição familiar com atuação na educação e sua concepção de educação é descrita como integral inovadora, abrangendo: "Promover o desenvolvimento integral dos estudantes, considerando todas as suas dimensões: intelectual, emocional, cultural, física e social; e responder às demandas do mundo contemporâneo e às especificidades do aluno do século $21^{19 \prime \prime}$. Ambos, Lemann e Inspirare, destacam que atuam "em parceria com Governos e outras entidades da sociedade civil20".

Todo o material disponibilizado pelo Movimento para "fazer a Base virar realidade" parte do conceito de competência constante no que foi denominado pelo MEC "versão definitiva" da Base (a terceira versão elaborada e encaminhada ao CNE). Até a segunda versão, o conceito de competência não tinha sido usado, sendo a Base estruturada em torno da noção de direitos de aprendizagem. No estudo comparativo publicado pelo MEC entre a $2^{\mathrm{a}}$ versão e a "definitiva", a opção pelas competências é justificada pelo fato de uma 
visão curricular referenciada em competências (...) [estar] já anunciada na Lei de Diretrizes e Bases da Educação Nacional (LDB) e presente na maior parte das propostas curriculares desenvolvidas no Brasil, nas reformas curriculares das últimas décadas empreendidas em diversos países e em avaliações internacionais (p. 8).

Ainda que o estudo comparativo minimize a guinada de direitos a competências, afirmando que ambos os conceitos "guarda[m] (...) grande proximidade", trata-se de uma mudança importante na luta política pela hegemonização de uma ideia de currículo nacional. A opção por um currículo guiado por direitos de aprendizagem, em que pese as críticas que apresento em outro lugar (Macedo, 2015), foi uma demanda de movimentos acadêmicos e sociais com vistas a distanciar a proposta da linguagem da testagem. Ao trazer de volta as competências - os PCN foram a primeira tentativa de hegemonizá-las -, a política curricular brasileira assume seus vínculos com um movimento internacional. que, sob a governança da OCDE, vem pondo em práticas avaliações internacionais comparativas. Junto-me a um conjunto de autores que avaliam tal movimento, notabilizado pela sigla Germ (movimento global de reforma da educação, em inglês), como um "vírus que mata a educação ${ }^{21 "}$ (Sahlberg, 2015).

É verdade que o termo competência é bem conhecido de educadores em muitas e diversas acepções - nos desdobramentos da racionalidade tyleriana nos anos 1970, no cognitivismo piagetiano, na tradição linguística de Chomsky e na discussão alemã no campo da formação profissional. No cenário internacional pós-1990, no entanto, ficou notabilizado pelos documentos da Unesco, especialmente o Relatório Delors. Noções como aprendizado ao longo da vida e sociedade do aprendizado (UNESCO, 1996), assim como a menção aos pilares da educação propostos pelo relatório - aprender a conhecer, aprender a fazer, aprender a viver junto e aprender a ser -, foram comuns nas políticas públicas do fim do século XX. Sem dúvida, já aí estava a ideia de que a educação é "estratégia chave para a produtividade econômica, o bem-estar individual e social e a inclusão socioeconômica" (TAKAYAMA, 2013: 60), ideia que se tornará mais forte, nas décadas seguintes, com o protagonismo da OCDE no cenário mundial.

O uso espraiado da noção de competência nos currículos nacionais não pode, portanto, ser deslocado do contexto em que a OCDE busca ampliar sua governança, não apenas por números e comparações (POPKEWITZe LIDBLAD, 2016), mas também por conceitos (Mausethagen, 2013). Talvez seja relevante destacar, como o fazem Sellar e Lingard (2013), tendo por referência um estudo de Carroll e Kellow, datado de 2011, que, com o fim da Guerra Fria, a OCDE precisou “estabelecer sua relevância no contexto da globalização" (p.713). Isso a fez se movimentar para áreas como educação e saúde pública, trazendo, para elas, as políticas economizantes e monetaristas pelas quais se notabilizou. Em relatório datado de 2012, a própria organização "reconhece que sem a redefinição [de sua estrutura e missão] ela teria se tornado irrelevante em face das mudanças econômicas globais" (ADDEY, 2017: 313). Addey (2017) vai defender que foi, "neste momento, que a OCDE passou a participar 
ativamente no desenvolvimento de uma agenda global para a educação, liderado pela Unesco, (...) como forma de garantir um lugar e uma voz clara" (p.313) na área.

A presença da OCDE como ator político "ajudou a formatar os sistemas educacionais que os governos nacionais deveriam criar para ampliar a produtividade e sustentar o crescimento econômico" (SELLAR e LINGARD, 2013: 722). Ao iniciar sua operação mais efetiva no campo da educação, ela "enfatizou a produção de capital humano como forma de neutralizar os efeitos da globalização" (NEIMANN e MARTENS, 2018: 272). Ao longo dos anos, como destacam inúmeros estudos (NIEMANN e MARTENS, 2018; ADDEY, 2016 e 2017; POPKEWITZ e LIDBLAD, 2016; LINGARD, 2016; MORGAN e VOLANTE, 2016; SELLAR e LINGARD, 2013; MAUSETHAGEN, 2013), a governança da OCDE no campo só fez aumentar, com efeito sobre as políticas nacionais. Há razoável consenso entre os pesquisadores de que ela vem sendo exercida de forma branda (soft governance), por meio da criação de uma linguagem internacional para a comparação de resultados educacionais.

Uma das principais ferramentas da OCDE para manter sua governança tem sido o Pisa. Como destacam Sellar e Lingard (2013), a testagem mobiliza a expertise da Organização na coleta e comparação de dados estatísticos, permitindo uma "governança infraestrutural" (p. 722). Ao mesmo tempo, ela exige e possibilita uma "governança epistemológica, que reflete sua bem-estabelecida capacidade de configurar as visões de atores chave em educação em escala local, nacional e global" (p.722). Por meio de propaganda bem estruturada, a OCDE vem difundindo, de forma "global, um tipo de racionalidade técnica weberiana como uma demonstração de modernidade de qualquer nação" (SELLAR e LINGARD, 2013: 618). Independentemente da importância dos dados obtidos na avaliação para a formulação das políticas nacionais, a participação no Pisa tem "legitimando a nova agenda educacional a favor de mais reformas escolares" (p.622), o que Sellar e Lingard (2013) chamam de uso "para fins de externalização" (p.621). De modo geral, essa posição é aceita por diversos estudos no campo das políticas educacionais. Addey (2017), por exemplo, vai defender que “a OCDE vem reforçando sua governança global ao estender o espaço global de comensuração em educação e introduzir sua métrica Pisa em avaliações nacionais de larga escala" (p. 311).

É no contexto do Pisa que a ideia de competências será retomada e desenvolvida por "comunidades epistêmicas de analistas de políticas, burocratas e políticos dentro da organização e nos países membros" (SELLAR e LINGARD, 2013: 712). Para Addey (2016), trata-se de um "empreendimento político compartilhado" (p. 690), pelo qual um modelo de política é hegemonizado. Um marco do protagonismo da OCDE no processo de significar competência foi a redação do documento que visava à "definição e seleção de competências" - DeSeCo (OCDE, 2005) -, no qual a organização pretendeu estabelecer as "fundações teóricas e conceituais" para o termo. De acordo com Scheiler (2007, citado por TAKAYAMA, 2013), neste documento, competências-chave foram definidas pela 
Organização como "a habilidade de, com sucesso, atender a demandas complexas pela mobilização de recursos psicossociais, incluindo conhecimento, habilidades, motivação, atitudes, emoções e outros componentes sociais e comportamentais" (p. 69). Um conjunto de nove competências (chave) foi distribuído, no DeSeCo, em três grandes grupos de comportamentos - agir autonomamente, usar ferramentas interativamente, funcionar em grupos socialmente heterogêneos (OCDE, 2005) - com destaque para dimensões psicossociais. Se comparado com seus documentos anteriores ${ }^{22}$, o DeSeCo representa uma guinada da OCDE na direção de um conceito mais amplo de competência. Anderson-Levitt (2017) argumenta que essa guinada surge num momento de agudização da crise financeira internacional, quando a retórica da empregabilidade que a competência garantiria se desgastou. Direitos humanos universais, cidadania global, inclusividade em diferentes âmbitos da vida e até felicidade surgem como as novas promessas.

Ao optar por usar o conceito de competência como articulador da BNCC, o MEC/ CNE se refere "a OCDE extensivamente como fonte de conhecimento, visando tanto à validação quanto à legitimação" (MAUSETHAGEN, 2013:165) de suas políticas, como ocorre em diversos outros países. A definição de competência da BNCC, reproduzida no material destinado aos docentes (nas páginas do MEC e do Movimento pela Base), guarda aproximações com as propostas da Organização: “a mobilização de conhecimentos, habilidades, atitudes e valores para resolver demandas complexas da vida cotidiana, do exercício pleno na cidadania e do mundo do trabalho ${ }^{23 \prime \prime}$. Ao mesmo tempo, no entanto, alguns elementos que marcam o que seria uma educação integral, na linguagem da OCDE, não parecem estar tão explícitos, quais sejam a preocupação com dimensões psicossociais ou com "emoções e outros componentes sociais".

Na fase de implementação, o material produzido pelo MEC e seus parceiros será mais explícito na referência à educação integral. Ao comparar a $2^{a}$ versão com a "versão definitiva" do documento, o MEC já atestava que "o conjunto de Competências gerais (...) amplia o conjunto de Direitos de aprendizagem e desenvolvimento da Versão 2 em três aspectos" (MEC, s/d: 8), dos quais destaco os dois últimos:

» Na consideração da importância da dimensão socioemocional na formação dos alunos, levando-os a se conhecer e a cuidar de seu bem-estar físico e emocional (Competência 8);

» Na ênfase sobre a importância de que os conhecimentos construídos na escola levem os alunos a agir com base em princípios éticos democráticos, inclusivos, sustentáveis e solidários (Competência 10) (MEC, s/d: 8).

Na sequência da implementação, acirram-se tais referências. No curso on-line disponível na página do Movimento, as competências são vinculadas à ideia de educação integral, definida como aquela que "leva em consideração o desenvolvimento dos 
estudantes em todas as suas dimensões: intelectual (...), física (...), emocional (...), social (...) e cultural ${ }^{24 \prime \prime}$. Tal vínculo fica ainda mais presente nos documentos que contam com a participação do Center for Curriculum Redesign, cuja atuação na significação do termo competência, ainda que não possa ser tratada aqui em profundidade, merece destaque.

O Center for Curriculum Redesign se define como "uma organização global sem fins lucrativos dedicada a melhorar a Educação via resposta para a questão: o que os alunos devem aprender para o século XXI?25", contando com financiamento da Fundação Henri Moser. Em 2015, o Centro lançou a volume Educação em quatro dimensões (FADEL, BIALIK e TRILLING, 2015), disponibilizado gratuitamente em português em razão de um acordo com os Institutos Península/Singularidades e Airton Senna, que traduziram a obra. No prefácio do livro, o Diretor de Educação e Habilidades da OCDE, Andreas Schleicher, atesta que

o projeto Educação 2030 da OCDE irá se basear neste trabalho do CCR de forma colaborativa, e a OCDE está atualmente desenvolvendo uma estrutura de competências, por meio de uma análise comparativa das estruturas de currículos internacionais. Contando com o poder de convocação da OCDE, a estrutura será testada, aperfeiçoada e validada de forma interativa com as partes interessadas de múltiplos níveis da comunidade global (p.13).

As quatro dimensões da educação para o século XXI são, segundo os autores da obra, conhecimento, habilidades, caráter e meta-aprendizagem. Conhecimento e habilidades são talvez as dimensões mais conhecidas e os autores pouco acrescentam aos sentidos que circulam na literatura sobre competências. Apesar de destacar a importância tanto dos conhecimentos quanto das habilidades - "criatividade, pensamento crítico, comunicação e colaboração" (p.118), Fadel, Bialik e Trilling (2015) vão afirmar que "as qualidades do caráter podem ser melhores indicadores do sucesso do estudante no aprendizado, no trabalho produtivo e na carreira, e também no engajamento ativo nas responsabilidades cívicas" (p.118 e 119). Por fim, a dimensão de meta-aprendizagem ${ }^{26}$ se apresenta como um desdobramento de ideias como reflexividade (OCDE), aprender a aprender (progressivismo) e aprendizagem ao longo da vida (UNESCO).

A defesa da multidimensionalidade do processo educativo não afasta os autores de uma visão comportamental de competências. Mesmo as qualidades de caráter "fazem parte da estrutura de objetivos educacionais - porque podem e devem ser atingidos e aprimorados por meio da prática" (p.120). Eles são apresentados como "indicadores de sucesso" - que é também o subtítulo do livro ${ }^{27}$.

A mesma ideia de que a competência - seja ela intelectual, física, emocional, social ou cultural - é "algo que um indivíduo atinge ou performa" (MAUSETHAGEN, 2013: 169), sem referência a nenhum contexto específico, está presente na BNCC. A exterioridade das competências em relação aos sujeitos é um dos aspectos que me parece problemático, especialmente quando se refere a "competências" como empatia ou curiosidade 
ou, nos termos do Center for Curriculum Redesign, à dimensão "caráter" do processo educativo. Em outro lugar (2013), argumentei que tal exterioridade põe no sujeito a culpa pelo fracasso das políticas públicas, que passa a ser visto como derivado de incapacidade individual de performar. Com a entrada em cena de competências emocionais ou sociais ou culturais, tal culpabilização se torna ainda mais intensa, posto que a incapacidade parece se localizar naquilo que é próprio dos sujeitos, por exemplo, suas emoções.

A exterioridade das competências fica clara no conjunto dos documentos no site do Movimento. Uma primeira estratégia nesse sentido, aparece no guia BNCC na prática: aprenda tudo sobre competências gerais (Nova Escola, s/d). Esse guia dá um "título [a cada competência], que sintetiza suas principais características" (p.5), com o objetivo de "facilitar o entendimento" (p.5) do que seja competência. Tais títulos - "conhecimento; pensamento científico, crítico e criativo; repertório cultural; comunicação; cultura digital; trabalho e projeto de vida; argumentação; autoconhecimento e autocuidado; empatia e cooperação; e responsabilidade e cidadania" (p.5) - são usados, posteriormente, em todo o material disponível no site. Para além de sintetizar as competências, eles redefinem o próprio sentido das 10 competências da BNCC. A título de exemplo, empatia e cooperação "representam" a competência

Exercitar a empatia, o diálogo, a resolução de conflitos e a cooperação, fazendo-se respeitar e promovendo o respeito ao outro e aos direitos humanos, com acolhimento e valorização da diversidade de indivíduos e de grupos sociais, seus saberes, identidades, culturas e potencialidades, sem preconceitos de qualquer natureza (Brasil, 2017).

Meu argumento é que, nessa "representação", desaparecem quaisquer contextos, permanecendo apenas uma característica subjetiva e individual ("caráter"?) que será mobilizada, no planejamento, como um comportamento. Para sustentar esse argumento, trago, como exemplo, um dos outros links da página do Movimento que disponibiliza uma plataforma que "busca apoiar redes e escolas a integrar melhor as Competências Gerais nos seus currículos ${ }^{28 \prime}$. Com ela, é possível "descobrir" combinações entre competências, habilidades e componentes disciplinares para os diferentes anos da escolarização. Mantendo o foco na competência 'empatia e cooperação' são dez as aprendizagens listadas, passíveis de serem trabalhadas em um ou mais campos disciplinares. Interessante notar que há campos disciplinares que parecem mais afeitos à competência e outros, como Língua Portuguesa, para o qual não se apresenta nenhuma combinação. Cito duas combinações "competências+habilidades" da disciplina História para o $5^{\circ}$ ano:

Identificar os processos de formação das culturas e dos povos, relacionando-os com o espaço geográfico ocupado reconhecendo e valorizando culturas e pontos de vista diversos. 
Identificar formas de marcação da passagem do tempo em distintas sociedades, incluindo os povos indígenas originários e os povos africanos, buscando interagir e aprender com outras pessoas, comunidades e culturas ${ }^{29}$.

Como tais objetivos/habilidades podem ajudar a desenvolver a competência 'empatia'? Na própria acepção comportamental de competência, valorizada pelo MEC na BNCC, comportamentos deste tipo referem-se a habilidades cognitivas das mais simples. Claro que se poderia argumentar que se trata apenas de um material sem qualidade, ainda que esteja sendo oferecido aos professores para seu planejamento e para a implementação da Base pela Undime. Não é, no entanto, apenas nessa plataforma que as competências psicossociais se materializam em habilidades comportamentais, individuais e externalizadas. A mesma estratégia pode ser vista no próprio documento aprovado pelo CNE. Defendo que se trata de uma característica da noção mesma de competência que tem sido posta em funcionamento pelo Germ que vai matando a educação, o germe da comparabilidade. Tal noção, como demonstra Mausethagen (2013), vem sendo "orientada pelo resultado individual e demonstrada por ações de sucesso de professores e alunos" (p.174).

Popkewitz e Lindblad (2016) hipotetizam que a "comparação é possivelmente o fardo da ciência social moderna" (p.733). Ela demanda estabilização e abstração, não pode lidar com o sujeito situado ou com a vida imprevisível. A comparação requer, e produz para existir, um genérico do sujeito, um nome sem face, o aluno competente (ou não). Com isso, ela torna a educação impossível, posto que não há educação - em si uma relação intersubjetiva - sem alteridade, sem o sujeito singular capaz de, e nem sempre, ser feliz, criativo, ter empatia, cooperar, amar. A OCDE vem tentando nos convencer de que não é possível fazer política pública de qualidade sem lançar mão das comparações. Estamos talvez diante de um impasse porque sabemos, há muito, que não é possível fazer educação (integral) sem gente de corpo e alma.

\section{E se os benchmarks fossem outros?}

Para finalizar, proponho aqui uma espécie de brincadeira, qual seja, usar a linguagem da OCDE, que populariza a comparação e o recurso a referências internacionais (benchmarks) para perguntar: e se os benchmarks fossem outros? Sem dúvida, um pouco dessa brincadeira já está em curso nas referências acadêmicas que, na seção anterior, pensam o lugar da OCDE na governança branda da educação, seja por intermédio dos números e das comparações, seja pela hegemonização de determinados conceitos como competência. Faço essa brincadeira, porque durante todo o processo de sua elaboração 
- e também agora - o recurso aos benchmarks internacionais foi uma das formas de buscar legitimar a BNCC.

A força simbólica de tais benchmarks está explicitada na página do Movimento por um link específico para as experiências internacionais ${ }^{30}$. Nele, Tracey McAskill e Phil Lambert discorrem sobre a implementação do currículo nacional australiano e Rebecca Kockler descreve o processo vivido no estado americano da Louisiana. Há, ainda, referência a uma instituição denominada Curriculum Foundation, sediada no Reino Unido, que atuaria na implementação de currículos ao redor do mundo, em especial na África e no Oriente Médio $^{31}$. O que quero aqui não é desqualificar as posições defendidas pelos colegas nos vídeos divulgados como benchmarks internacionais, mas complicar a própria produtividade da apresentação de tais referências. Não bastasse o fato de não haver consenso, nesses países, sobre a experiência de produzir currículos centralizados (REID e PRICE, 2017; RAVITCH, 2015; PRICE, 2014), a própria ideia de referência só faz sentido no âmbito da comparação que a OCDE hegemonizou. Por outro lado, por que ter como referência contextos nacionais/estaduais que não estão na liderança nos estudos comparativos?

Na lógica de competitividade que a OCDE implanta, não faltam estudos que olham para os melhores como exemplos, não propriamente a seguir, mas a superar. Sellar e Lingard (2013) resumem estudo encomendado pelo governo norte-americano, publicado em volume organizado por Tucker (2011, citado por SELLAR e LINGARD, 2013), destacando que os principais fatores de sucesso das reformas parece ser "conjunções de cultura e contexto (...) e o foco na qualidade dos professores" (p.718). Finlândia, Shangai, Singapura e Japão partilhavam, segundo os autores, um contexto cultural de alta valorização da educação e da profissão docente. Uma das conclusões dos benchmarks estudados é a necessidade de "políticas de formação e remuneração de professores (...) que elevem o status da docência como profissão, de modo a atrair os candidatos academicamente mais fortes para instituições de treinamento e a encorajar formas colegiadas de responsabilização e pesquisa" (p.718). Na introdução do volume, Linda-Darling Hammond, um dos nomes mais respeitados no estudo das políticas educacionais americanas, "mostra como as estratégias da recente reforma educacional dos EUA contrasta claramente com as levadas a cabo pelos sistemas com melhor performance" (SELLAR e LINGARD, 2013: 717). O país ficou entre o $23^{\circ}$ e $24^{\circ}$ lugar no ranking do Pisa (LINGARD, 2016) e na avaliação do desempenho dos sistemas educacionais por estado, realizada pela National Education Association (NEA, 2019), a Louisiana está posicionada na metade inferior em quase todos os quesitos avaliados. Por que seria este, então, um benchmark para a experiência brasileira? Por que não tomamos as experiências dos quatro países/cidades que estão resenhados por seus resultados?

Do conjunto desses países/cidades com alto desempenho, a Finlândia é talvez o mais conhecido, não apenas pelos excelentes resultados no Pisa, mas por obtê-los a partir de políticas curriculares não centralizadas. Sahlberg (2015) - formulador de políticas 
em órgãos internacionais e no Ministério da Educação da Finlândia - descreve a excelência do sistema do país da seguinte forma:

\begin{abstract}
A Finlândia criou programas de formação de professores internacionais. E a Finlândia paga bem a seus professores. Mas a diferença é que os professores na Finlândia podem exercer seu julgamento profissional tanto amplamente quando livremente nas escolas. Eles controlam o currículo, a avaliação dos alunos, as melhorias da escola e o envolvimento da comunidade (p.7).
\end{abstract}

Ao resumir as lições da Finlândia, Sellar e Lingard (2013) destacam a "sinergia, uma complementariedade real e significante, entre a educação e outras políticas sociais" (p. 721). O impacto de um conjunto mais amplo de políticas sociais - que minimizem as desigualdades - na qualidade da educação é um dos aspectos mais destacados por Salhberg (2011) em suas Lições Filandesas. Como lembra Lingard (2016), baseado em um estudo de Meyer e Schiller (2013, citado por LINGARD, 2016), "as análises da OCDE sobre o Pisa tendem a (...) subestimar as desigualdades estruturais" (p. 617). Ao mesmo tempo, estudos de países distintos como Noruega (MAUSETHAGEN, 2013), Japão (TAKAYAMA, 2013) e EUA (RAVITCH, 2013) vêm indicando que não tem havido redução das desigualdades (ao contrário, ela segue crescendo) quando se aplicam políticas curriculares e de avaliação centralizadas nos moldes tornados hegemônicos pela OCDE.

Há nessas experiências internacionais, me parece, sugestões políticas relevantes. Talvez, no entanto, elas apenas repitam o que nossas pesquisas e os resultados das avaliações centralizadas do próprio MEC vêm destacando há muitas décadas: que precisamos de uma Base para a educação no País. A base é uma universidade que forme professores num ambiente de pesquisa e cultura. A base é a dedicação exclusiva do professor a uma escola, salário que permita a esse professor uma vida digna (em que a gente não quer só comida, mas diversão e arte). A base é alunos que podem comer e recebem ação do Estado no atendimento de suas necessidades básicas de saúde, saneamento e cultura. A base é escolas com boas condições materiais e de infraestrutura. Isso é base, o que tem sido chamado de Base é a pretensão de definir o horizonte logo ali onde os olhos do controle podem alcançar. Nós, no entanto, insistimos em dizer que o horizonte não é um, nem logo ali. Meninos, a Terra não é plana!

Recebido em: 25/05/2019 e aprovado em: 03/06/2019

\title{
Notas
}

1 Projeto de pesquisa financiado pelo CNPq, pela Faperj e pelo programa Prociência da UERJ. 
2 http://basenacionalcomum.mec.gov.br/implementacao/. Acessado em 22 de abril 2019.

3 Exploro esta ideia melhor em Macedo (2018a).

4 Venho trabalhando na análise do processo político que culminou na BNCC com três conjuntos de demandas: por accountability, por justiça social e por liberdade (como tem se autodenominado as demandas conservadoras). No atual momento político, as demandas por justiça social têm perdido espaço e sido mesmo apresentadas como o exterior constitutivo das demandas por liberdade (MACEDO, 2018b).

5 Na ocasião, foram definidas também as metas do programa no que concerne ao ensino médio. No mesmo movimento, foi modificada a composição do Comitê Nacional de Implementação da BNCC (Portaria 757, MEC, 2019).

6 Aqui, eu estaria sugerindo uma distinção entre a racionalidade neoliberal e o discurso ultra-liberal que tem acompanhado os populismos de direita. Em linhas gerais, chamo de ultra-liberais demandas pela drástica redução do tamanho e da regulação do Estado, especialmente nas questões ambientais e trabalhistas. Nesse sentido, manifestar-se-iam em contrário à hegemonia neoliberal (entendida como globalista) por esta ter "cedido" em tais questões, assim como em questões envolvendo racismo e imigração.

7 Quero aqui destacar que também estes coletivos - Consed e Undime - são plurais e, como todos os espaços sociais, marcados por antagonismos. Portanto, não quero sugerir que a posição que aqui apresento como do Consed e da Undime seja uma posição unânime no conjunto de secretários. Agradeço a colegas secretárias de educação de munícipios da Bahia por me alertar para a necessidade desta nota.

8 http://www.consed.org.br/media/download/5ca6622bc9936.pdf. Acesso em 01 de maio de 2019.

9 http://www.consed.org.br/portal/noticia/mec-reune-secretarios-de-educacao-e-entidades-do-terceirosetor-para-trabalhar-agenda-conjunta. Acessado em 01 de maio de 2019.

10 Apenas a título de exemplo, o Seminário de Formação Continuada para os Novos Currículos, com a presença da Undime e Consed, foi promovido pela Fundação Lemman em abril de 2019 (https://undime.org. br/noticia/17-04-2019-14-59-formacao-continuada-para-os-novos-curriculos-e-tema-de-seminario. Acessado em 1 de maio de 2019)

11 http://movimentopelabase.org.br/quem-somos/. Acessado em 01 de maio de 2019.

12 http://movimentopelabase.org.br/implementacao/. Acessado em 01 de maio de 2019.

13 Os demais links são: quem somos, biblioteca, acontece e na prática.

14 https://implementacaobncc.com.br/wp-content/uploads/2018/06/guia_de_implementacao_da_bncc_2018. pdf. Acessado em 01 de maio de 2019.

15 https://bncc.novaescola.org.br/. Acessado em 01 de maio de 2019.

16 https://cursos.novaescola.org.br/curso/12/competencias-gerais-na-bncc/resumo?logged=false. Acessado em 01 de maio de 2019.

17 http://s3.amazonaws.com/porvir/wp-content/uploads/2018/02/28185234/BNCC_Competencias_Progressao.pdf. Acessado em 01 de maio de 2019.

18 http://www.competenciasnabncc.org.br/. Acessado em 01 de maio de 2019.

19 http://inspirare.org.br/wp-content/uploads/2018/05/documento-educacaointegralinovadora-inspirare. pdf. Acessado em 01 de maio de 2019.

20 https://fundacaolemann.org.br/somos. Acessado em 01 de maio de 2019.

21 Essa imagem foi notabilizada por Pasi Sahlberg, acadêmico com larga experiência em política pública na Finlândia e em organismos internacionais. https://pasisahlberg.com/global-educational-reform-movement-is-here/. Acessado em 01 de maio de 2019. 
22 Em 1995, as competências eram referidas diretamente às "necessidades dos empregadores e à capacitação dos estudantes para o mercado de trabalho". Em 2000, a definição passou a ser influenciada pelo Pisa: padrões de medida capazes de "medir não a maestria no currículo escolar", mas os "conhecimentos e habilidades necessárias para a vida adulta"' (OCDE, 2000: 8).

23 http://basenacionalcomum.mec.gov.br/images/BNCC_AS_DEZ_COMPETENCIAS.mp4. Acessado em 01 de maio de 2019 .

$24 \mathrm{https} / /$ cursos.novaescola.org.br/curso/12/competencias-gerais-na-bncc/108/apresentacao. Acessado em 01 de maio de 2019.

25 https://curriculumredesign.org/about/. Acessado em 01 de maio de 2019.

26 Dado um conjunto de referências na página do Centro à neurociência e à inteligência artificial, tal dimensão pode permitir outras análises que fogem aos objetivos deste texto.

27 O subtítulo do livro é 'as competências que os estudantes precisam ter para atingir o sucesso'.

28 http://www.competenciasnabncc.org.br/sobre. Acessado em 01 de maio de 2019.

29 http://www.competenciasnabncc.org.br/combine/competencia. Acessado em 01 de maio de 2019.

30 http://movimentopelabase.org.br/implementacao/. Na página implementação, há quatro grandes temas: guia redes; $\mathrm{BNCC}$ em profundidade, competências gerais e benchmarks internacionais sobre a implementação (como fazer a base chegar na sala de aula?). Acessado em 01 de maio de 2019.

31 https://www.curriculumfoundation.org/. Acessado em 01 de maio de 2019.

\section{Referências}

ADDEY, Camila. O PISA para o desenvolvimento e o sacrifício de dados com relevância política. Educação \& Sociedade, Campinas: CEDES, v. 37, n. 136, p. 685-706, 2016.

ADDEY, Camila. Golden relics \& historical standards: how the OECD is expanding global education governance through PISA for Development. Critical Studies in Education, v. 58, n. 3, p. 311-325, 2017. DOI: https://doi.org/10.1080/17508487.2017.1352006.

ANDERSON-LEVITT, Kathryn . Global Flows of Competence-based Approaches in Primary and Secondary Education. Cahiers de la recherche sur l'éducation et les savoirs, v.16, n. 1, p. 47-72, 2017.

AVELAR, Marina \& BALL, Stephen. Mapping new philanthropy and the heterarchical state: The Mobilization for the National Learning Standards in Brazil. International Journal of Educational Development, v. 64, p. 65-73, 2019.

BALL, Stephen J. Global education Inc.: new policy networks and the neoliberal imaginary. New York: Routledge, 2012.

BALL, Stephen. J. \& JUNEMANN, Carolina. Networks, new governance and education. Bristol: The Policy Press, 2012.

BRASIL. Base Nacional Comum Curricular: Educação é a Base. Brasília: MEC/CONSED/UNDIME, 2017. Disponível em: http://basenacionalcomum.mec.gov.br/images/BNCC_EI_EF_110518_ versaofinal_site.pdf. 
FADEL, Charles; BIALIK, Maya \& TRILLING, Bernie. Educação em Quatro Dimensões: As competências que os estudantes devem ter para atingir o sucesso. Boston: Center for Curriculum Redesign, 2015.

HYPÓLITO, Alvaro Luiz M. Trabalho docente e o novo plano nacional de educação: valorização, formação e condições de trabalho. Cadernos Cedes, Campinas: CEDES, v. 35, n. 97, p. 517-534, 2015.

LACLAU, Ernesto. Emancipação e diferença. Rio de Janeiro: EdUERJ, 2011.

LINGARD, Bob. PISA: Fundamentações para participar e acolhimento político. Educação \& Sociedade, Campinas: CEDES, v. 37, n. 136, p. 609-627, 2016.

LOPES, Alice Casimiro. Normatividade e intervenção política: em defesa de um investimento radical. In: LOPES, Alice Casimiro; MENDONÇA, Daniel de. (Org.). A Teoria do Discurso de Ernesto Laclau: ensaios críticos e entrevistas. São Paulo: Annablume, 2015. p. 117-147.

MACEDO, Elizabeth. Equity and difference in centralized policy. Journal of Curriculum Studies, v. 45, n. 1, p. 28-38, 2013.

MACEDO, Elizabeth. Base Nacional Curricular Comum: novas formas de sociabilidade produzindo sentidos para educação. E-Curriculum, São Paulo: PUC-SP v. 12, n. 3, p. 1530-1555, 2014.

MACEDO, Elizabeth. Base Nacional Comum para Currículos: direitos de aprendizagem e desenvolvimento para quem? Educação e sociedade, Campinas: CEDES, v. 36, n. 133, p. 891-908, 2015.

MACEDO, Elizabeth. "A Base é a base." E o currículo, o que é? In AGUIAR, Marcia Angela da S. \& DOURADO, Luiz Fernando (orgs.). A BNCC na contramão do PNE 2014-2024: avaliação e perspectivas. Recife: ANPAE, 2018a. p. 28-33.

MACEDO, Elizabeth. Repolitizar o social e tomar de volta a liberdade. Educação em Revista, Belo Horizonte: UFMG, v. 34, p. 1-15, 2018b.

MAUSETHAGEN, Sølvi. Governance through concepts: The OECD and the construction of competence in Norwegian education policy. Berkeley Review of Education, v. 4, n. 1, p. 161-181, 2013.

MEC. Base Nacional Curricular Comum. Brasília: MEC, 2015.

MEC. Portaria 757. Brasília: MEC, 2019.

MEC. BNCC Educação é a Base: Estudo comparativo entre a versão 2 e a versão final. Brasilia: MEC, s/d.

MORGAN, Clara \& VOLANTE, Louis. A review of the Organisation for Economic Cooperation and Development's international education surveys: Governance, human capital, discourses, and policy debates. Policy Futures in Education, v. 14, n.6, p. 775-792, 2016. DOI: https://doi. org/10.1177/1478210316652024.

MOUFFE, Chantal. For a left populism. Londres: Verso, 2018.

NATIONAL EDUCATION ASSOCIATION (NEA). Rankings of the States 2018 and Estimates of School Statistics 2019. Washington: NEA, 2019.

NIEMANN, Dennis \& MARTENS, Kerstin. Soft governance by hard fact? The OECD as a knowledge broker in education policy. Global Social Policy, v. 18, n. 3, p. 267-283, 2018. DOI: https://doi. org/10.1177/1468018118794076.

ORGANIZATION FOR ECONOMIC COOPERATION AND DEVELOPMENT (OECD). Measuring student knowledge and skills, Paris: OECD, 2000. 
ORGANIZATION FOR ECONOMIC COOPERATION AND DEVELOPMENT (OECD). The Definition and Selection of KCs: Executive Summary. Paris: OECD, 2005.

POPKEWITZ, Thomas \& LINBLAD, Sverker. A fundamentação estatestica, o governo da educação e a inclusão e exclusão sociais. Educação \& Sociedade, Campinas: CEDES, v. 37, n. 136, p. 727-754, 2016.

PRICE, Todd ALAN. Comum para quem? Revista e-Curriculum, São Paulo: PUC-SP, v. 12, n. 3, p. 1614-1633, 2014.

RAVITCH, Diane. Reign of erros: The hoax of the privatization movement and the danger to America's public schools. New York: Random House, 2013.

REID, Alan \& PRICE, Deborah (Orgs.). The Australian curriculum: Promises, problems and possibilities. Sydney: AACS, 2017.

SAHLBERG, P. Finnish Lessons 2.0. Nova York: Teachers College Press, 2015.

SELLAR, Sam \& LINGARD, Bob. The OECD and global governance in education, Journal of Education Policy, v. 28. n. 5, p. 710-725, 2013. DOI: https://doi.org/10.1080/02680939.2013.779791.

SHIROMA, Eneida O. Networks in action: new actors and practices in education policy in Brazil. Journal of Educational Policy, v. 29, n. 3, p. 323-348, 2013. DOI: https://doi.org/10.1080/02680939.2013 .831949 .

TAKAYAMA, Keita. OECD, Key competencies and the new challenges of educational inequality. Journal of Curriculum Studies, v. 45, n.1, p. 67-80, 2013. DOI: https://doi.org/10.1080/00220272.2012.7 55711 .

UNESCO. Learning: The Treasure Within. Paris: UNESCO, 1996. 